\title{
A Força do Lugar Como Aporte à Educação Integral
}

\section{A Place of Strength as Contribution to the Integral Education}

\section{Resumo:}

Afirmando um sentido dialético-dialógico de lugar, este ensaio teórico resulta de pesquisa bibliográfica que estabelecemos em diálogo com nossas vivências de professoras-pesquisadoras. Pautando-nos, especialmente, em referenciais da Geografia e da Filosofia, argumentamos o lugar como fundamental à educação integral dos sujeitos, considerando que essa noção implica a compreensão da dimensão espaço-temporal que envolve as relações elaboradas pelos sujeitos em interação, como nós dialógicos. Essa perspectiva é elaborada, enlaçada em aportes que servem conceitualmente às aprendizagens propostas em todos os componentes curriculares. Assim, organizamos este texto trazendo o debate sobre a importância do lugar à educação integral e os princípios científico-didáticos que embasam a noção de lugar, para afirmar sua potência nos processos de ensino.

\begin{abstract}
:
Affirming a dialectical - dialogic sense of place, this theoretical essay results from literature, we have established a dialogue with our experiences of teachers -researchers. Guided us, especially in reference Geography and Philosophy, we argued the place as fundamental to the integral education of the subjects, considering that this notion implies the understanding of space - time dimension which involves the relationships developed by the subjects interacting as we dialogic. This perspective is drawn up, elaborately in contributions that conceptually serve the proposed learning in all curriculum components. So we organized this text bringing the debate on the importance of place to the integral education and scientific and didactic principles that support the place to assert his power in educational processes.
\end{abstract}

Adriana Maria Andreis * Helena Copetti Callai **

* Doutora em Educação nas Ciências- área de concentração Geografia pela UNIJUÍ/ RS. Professora do curso de Geografia na Universidade Federal da Fronteira Sul UFFS - Campus Chapecó/ SC.

** Doutora em Geografia pela USP/SP e bolsista produtividade CNPq. Professora no Programa de Educação nas Ciências na Universidade Regional do Noroeste do Estado do Rio Grande do Sul UNIJUÍ/RS

Palavras-chave:

Espaço-Tempo

Ensino-aprendizagem Princípios científico-didáticos da Geografia, Educação Básica.

Key-Words:

Space -Time, Teaching and Learning, Scientific and Didactic Principles of Geography, Basic Education. 


\section{INTRODUÇÃO}

“- A gente não tem mais lugar nesta escola!"

E sse enunciado foi expresso, em tom baixo e compassado, por uma aluna do segundo ano do Ensino Médio ${ }^{1}$, logo que ingressou e se acomodou na carteira à esquerda do laboratório de Geografia. Escutamo-lo no período em que a escola implantava o modelo que comumente se denomina de salas-ambiente. Nesse sistema, as aulas passam a acontecer em salas organizadas especialmente para cada componente curricular. Assim, quando ocorre troca de disciplina, os alunos se dirigem às salas destinadas a cada disciplina; ou seja, não são os professores que se dirigem à sala das turmas de alunos, são os alunos que se deslocam ao encontro das aulas e dos professores nas respectivas salas-ambiente. Tomamos a frase da aluna, que nos serve de introito à argumentação, para pensar sobre o lugar como aporte à educação integral. Para isso, tendo como horizonte a perspectiva de uma educação integral, pensamos nas contribuições, compromissos e possibilidades da Geografia no sustento epistemológico dessa noção.

Essa reflexão dialoga com o que compreendemos como sendo "lugar", para além da espontaneidade e da mera localização. Para esse percurso, assumimos o lugar como um aporte potente à educação integral, porque sua natureza é geográfica. Sendo o lugar espaço-temporal, é constitutivo dos sujeitos e, assim, coimplica todos os componentes curriculares. Pois, com esse sentido, construímos uma argumentação na qual apresentamos algumas ideias acerca do lugar e sua sustentação teórica em princípios científico-didáticos, para afirmarmos sua importância às aprendizagens escolares.

Identificação e pertencimento ao lugar não devem ser confundidos com aprisionamento a um local, pois, como lembra a inferência literária de Dostoyevski (1976, p. 126, grifo nosso) "[...] ainda que em lugares conhecidos e familiares se passem apuros, sempre será melhor que estar em um lugar novo e desconhecido." Evitando esse risco, para esta argumentação, assumimos o papel da escola como processo centrado no pensar, ou seja, no "experimentar posicionamentos outros” (BAKHTIN, 2005). Isso porque a dimensão de "lugar" conversa com a ideia de "vivido e experimentado", mas, também, essa proximidade dialoga com a acomodação, que põe limite ao pensar. Com essas ideias, desencadeamos a afirmação de que a escola e as aulas têm, sim, um papel propositado de tensionar os sentidos e significados dos sujeitos e, por meio de conhecimentos conceituais, provocar incômodos e desacomodações.

\section{O LUGAR À EDUCAÇÃO INTEGRAL: CON- TRIBUIÇÕES DA GEOGRAFIA}

Implicado na complexidade constitutiva dos sujeitos, o lugar pensado como aporte à educação integral compreende um princípio educativo que na escola, vai além da ideia de integração entre os conhecimentos das diversas áreas. Trata-se de assumir que todos vivem em relações nas quais o lugar é um produto que vai sendo configurado pelos sujeitos em interação, mas é também produtor da vida dos sujeitos, por isso envolve sentidos e significados, na escola e nas aulas, especialmente dos alunos e professores. Assim, lugar é assumido como referente de emancipação, porque pautado na libertação do pensar.

Esse entendimento compreende uma natureza epistemológica de integralidade, pois envolve a noção de que lugar é elo multidimensional, multirreferencial e multiescalar à construção de conceitos pelos sujeitos da aula, simplesmente porque compreende, inescapavelmente, a vida das pessoas. Bakhtin (2010, p. 108) é enfático ao afirmar que “[...] a abstração de si é um artifício técnico, que encontra justificação já desde o meu lugar único, onde eu, que conheço, e me torno responsável e obrigado por esse conhecimento." Afirmando a força da singularidade de cada sujeito, que vive permanentemente relações com a dimensão do lugar, o pesquisador refere:

Desde o momento em que a teoria se separa do ato e se de-
senvolve segundo a sua lei interna imanente, o ato mesmo,
desembaraçando-se da teoria começa a degradar-se. Todas as
forças de realização responsável [...] se retiram para o territó-
rio autônomo da cultura e o ato separado delas degenera ao
grau de motivação biológica e econômica elementar, perdendo
todos os seus componentes ideais. [...] A teoria deixa o ato a
mercê de uma existência estúpida, exaure-o de todos os seus
componentes ideias e o submete a seu domínio autônomo fe-
chado, empobrece o ato. (BAKHTIN, 2010, p. 116).

O entendimento da teoria separada do ato aproxima-se do entendimento e tratamento do lugar como mera localização e exemplificação, pois, esvaziando-o de sentido e, empobrecendo o ato, reduzem-se muito as possibilidades de atribuição de significados conceituais com maior generalidade e complexidade. Lugar é dimensão espaço-temporal que envolve a vida e todos os conceitos propostos pela escola, e isso implica sustentação das aulas, independentemente da adoção, ou não, da escola de tempo integral ${ }^{2}$. 
Lugar é chave de abertura, visto que “[...] não há nenhuma utilidade para os alunos em se construir um currículo em torno da sua experiência, para que este currículo possa ser validado e, como resultado, deixá-los sempre na mesma condição.” (YOUNG, 2007, p. 1297). Assim, lugar não deve ser reduzido à mera localização nem encerrado em um local, mas deve se constituir na relação dialética oportunizada pelo diálogo, para ser um dos pontos de referência.

Considerando que todos os sujeitos convivem em relações com lugares, o reconhecimento dessa noção é pressuposto para “[...] uma prática pedagógica que afirme a educação como direito de todos e de cada um.” (BRASIL, 2009, p. 09). Trata-se de práxis pedagógica, que não começa nem termina apenas em direitos e obrigações legalmente elencados, mas envolve, sim, ter acesso e compreender os conhecimentos e os processos de mediação como diferentes proposições de leituras de mundo, com os quais as áreas e componentes educativos realizam esforços para provocar confroencontros entre ideias. E estas devem estar assentadas no reconhecimento das singularidades e complexidades espaço-temporais dos sujeitos e dos conhecimentos, tendo como princípio a libertação. É assim que a educação integral pode ser entendida como princípio que “[...] reconhece que os estudantes são sujeitos de vivências que [...] dependem de processos educacionais intencionais abrangentes e da abertura do espaço escolar." (ibidem, p. 49). E isso expressa a importância do lugar como noção dialético-dialógica, que não deve ser confundida com localização pontual, como encerramento a uma sala, carteira ou cadeira, dimensão à qual inferimos ter se referido a aluna do Ensino Médio no início deste texto.

Nas aulas da Educação Básica, da graduação e, inclusive, da pós-graduação, todos os sujeitos sempre estão em vinculações que coimplicam lugares nos quais e com os quais acontecem confroencontros (ANDREIS, 2014b) de relações. Essas relações implicam movimentos que podem, até mesmo, acontecer de modo rotineiro - como em relação aos horários escolares, as pessoas e os objetos com os quais nos confroencontramos diariamente -, mas ocorrem, sempre, de modo exclusivo e provisório, ainda que envolvam algum local de referência que, também, nunca se repete.

Repetibilidade e igualdade inexistem (ANDREIS, 2014a) em relação a espaço-temporalidade, por isso, em relação ao lugar que lhe é constitutivo, fixidez também inexiste. E entender esse sentido, que avança da mera localiza- ção, cabe, especialmente, à Geografia, que é a ciência que o discute sistematicamente. Nessa perspectiva, lugar deve ser assumido não apenas como tematização, mas como modo de abordagem epistemológica e metodológica dos conhecimentos que, a cada aula, são postos em questão. Isso não coaduna com o entendimento de "lugar" como encerramento ao local, mas conjuga com o sentido de abertura e generalidade, implicado no reconhecimento da singularidade, assentado no compromisso com o diálogo.

O problema histórico reside em restringir "lugar" a "localização", mesmo que essa localização seja assumida como movimento de entrecruzamento com o global. Por isso, talvez, possamos dizer que cabe à Geografia ao menos parte dessa responsabilidade em contribuir com o debate acerca do entendimento da categoria "lugar". A nossa argumentação da noção de "lugar" envolve compreensões abrangentes que entrelaçam História, Sociologia, Filosofia, Biologia, Artes e outras áreas, porque o mundo colocado em questão nas aulas e os alunos que as frequentam são os comuns nas diferentes disciplinas. Porém, entendemos que cabe à Geografia boa parte da responsabilidade de tensionar conceitualmente "lugar", para servir como aporte às demais áreas.

Cabe lembrar que "lugar" é uma noção identificadora da Geografia, tanto assim que o mapa e o globo, especialmente, por serem veículos que expressam as localizações, muitas vezes são utilizados como símbolo dessa ciência. De fato, ambos são geográficos, mas são também históricos, sociológicos, biológicos, físicos, químicos e matemáticos; da mesma forma, são políticos, sociais, demográficos, culturais - pois com essas elaborações todas as áreas estão implicadas. Também, servem às outras áreas e, ainda assim, para além de todas as compreensões e interpretações envolvidas, são relacionados com a geografia e com o lugar, porque tudo o que existe compreende relações com uma localização, nunca como limite, mas como elo dialógico.

Lugar é um modo de abordar a espacialidade, colocando acento nos confroencontros de relações, que se configuram como nós espaço-temporais, permanentemente em elaboração - por isso, tal noção implica uma dialética-dialógica. Com base nesse entendimento, lugar é uma possibilidade a ser assumida: como modo de ler a espaço-temporalidade pelo viés geográfico no ensino ${ }^{3}$. Esse é o compromisso da aula de Geografia, que contribui para a formação integral dos sujeitos.

A aula é parte da escolaridade do aluno, e as discipli- 
nas têm um compromisso significativo no sentido de contribuir na formação do sujeito. A Geografia, por sua vez, como disciplina escolar, é ligada à ciência geográfica, que é um dos recortes acadêmicos para interpretar o mundo e, como tal, tem uma história que expressa os fundamentos que a sustentam. Essa perspectiva assentada na especificidade da Geografia se encontra com o argumento de Young (2011, p. 614) de que "[...] o conhecimento incluído no currículo deve basear-se no conhecimento especializado desenvolvido por comunidades de pesquisadores." Pauta-se esse entendimento nos argumentos que envolvem:

(a) as diferenças entre formas de conhecimento especializado $\mathrm{e}$ as relações entre elas; (b) como esse conhecimento especializado difere do conhecimento que as pessoas adquirem no seu cotidiano; (c) como o conhecimento especializado e o cotidiano se relacionam entre si [...] (YOUNG, 2007, p. 1295-1296).

Essas afirmações permitem pensar o lugar tanto como referente de cotidiano quanto como elo com os conhecimentos diferentes do cotidiano. Ao encontro dessas possibilidades, Santos (2004) afirma que, diante da fragmentação das disciplinas, o nosso objeto permite buscar as formas integradoras para entender o mundo em que se vive. $\mathrm{O}$ objeto a que o pesquisador se refere é o espaço que coimplica tempo. No caso desta pesquisa, consideramos que o espaço integra os momentos anteriores e passa a ser o lugar de encontro entre esse passado e futuro, através das relações sociais do presente; que é resultado-produto das vidas vividas, mas é também palco onde são vividas as vidas; que não é um espaço inerte, mas dinâmico, que interfere nas condições de realização das ações das pessoas, dos grupos sociais.

Enfim, são relações humanas que se materializam provisoriamente em espaço, criando formas visíveis materiais, virtuais ou intangiveis, e que se abrem necessariamente para acolher e para fazer o novo, o agir e ao mesmo tempo podem impor limites ou favorecer as realizações. A Geografia pode, então, ser o componente curricular que proporciona a compreensão do mundo, propiciando um repertório que permite pensar sobre os problemas da sociedade e buscar soluções. Mas, basicamente, esperamos com a aula de Geografia que o aluno entenda a realidade em que vive e consiga fazer a abstração necessária para formulação dos conceitos - elaborações conceituais matemáticas, físicas, químicas e históricas, entre outras. E, neste contexto das relações sociais, consideramos "lugar" como o conceito eleito para a análise das práticas escolares na escola.

A rede conceitual da ciência deve funcionar como constituinte dos conteúdos da prática científica e do ensino-aprendizagem dela. E com essa postura intelectual, que leva a abstração para além do senso comum, é que pode ser tra- balhada a Geografia escolar numa perspectiva científica. O conceito de "lugar", então, nos desafia a fazer um ensino que possa contribuir com a formação dos alunos na constituição da sua cidadania. Neste sentido, a Geografia não pode ficar restrita a olhar, descrever, analisar os espaços conhecidos, ou as paisagens, mesmo que distantes, pois dessa forma estaremos apenas e sempre centrando o conteúdo pela informação em si.

A dimensão do lugar antecede tanto a definição dos conteúdos como a forma de trabalhar com eles: em um nível mais teórico, no qual a abstração fundamente o uso dos conceitos. A partir daí, cria-se a possibilidade de compreender os elementos empíricos no contexto de sua história, da história dos sujeitos e da sociedade. Os conteúdos com que trabalhamos são sempre resultados da tradição, portanto são produções históricas e sempre estão em movimento.

Pensamos o lugar em relação intrínseca com a educação integral, porque “[...] consideramos que a leitura do mundo é fundamental para todos nós, que vivemos em sociedade [...]" (CALLAI, 2005, p. 228), e que é na relação com o lugar que os conhecimentos conceituais dotados de generalidade são prospectivamente construídos. Por isso, é importante compreender os princípios que sustentam teoricamente a noção de "lugar", pois interessa à aprendizagem em todas as áreas do conhecimento escolar.

\section{ENLACES EM PRINCÍPIOS CIENTÍFICO- -DIDÁTICOS}

Lugar como pontos nodais de entrelaçamentos de relações dinâmicas e dialéticas, com resultados imprevisíveis, é nosso argumento para pensá-lo na perspectiva espaço-temporal, assumindo-o como diálogo. Isso porque se assenta no pressuposto que reconhece o lugar como confroencontro das relações de vida, tecidas como espacialidade. Essa sustentação epistemológica se enlaça em princípios geográficos elaborados socialmente, entendidos como ideias provisórias mas fundamentais, e que orientam os pensamentos e os modos de pensar. Consideramos provisórias essas ideias porque não acreditamos em verdades absolutas.

A história é elaboração dos humanos e, neste sentido, as regras, as leis, os princípios que fundamentam a interpretação são sempre dinâmicos e têm o movimento da própria sociedade. O mundo não é um mundo em si, mas uma acepção de mundo e, neste sentido, "A multiplicidade de acepções de mundo não significa relativização, mas, ao contrário, o que o mundo é não se distingue das acepções que dele se oferecem." (HERMANN, 2003, p. 99). Tais acepções constituem a vida de cada pessoa e, por isso, são elos no ensino, servindo como chaves de abertura às aprendizagens, em todas as dis- 
ciplinas escolares.

García Ruiz (2012, p. 49-50) propõe dez aportes teórico-epistemológicos que sustentam os princípios: universalidade; espacialidade; temporalidade; conflito-consenso (modalidade); atividade, evolução, mudança e continuidade; intencionalidade; interdependência; causalidade; identidade; relatividade. É assim que García Ruiz e seu grupo de pesquisadores propõem a espaço-temporalidade como sustentáculo desses princípios:

[...] podemos concordar que a temporalidade, a espacialidade, a causalidade, a interdependência, a intencionalidade, a mudança-continuidade e a identidade, são componentes inerentes ao conhecimento geográfico-histórico. Falarmos em temporalidade pode ser considerado como um movimento próprio do campo social. Porém, de qualquer modo, essa temporalidade não é o tempo com o qual trabalham os geólogos, nem com aquele que operam os biólogos. É um tempo social específico, o tempo dos homens, das sociedades e das culturas, com seus movimentos, seus ritmos, suas intensidades, seus saltos, seus retrocessos, suas constantes e suas variantes, sua sincronia e assincronia. Assim, poderíamos seguir analisando a espacialidade (como fazeres e usos que dela fazem as sociedades), a causalidade (a multicausalidade, o entrecruzamento, as cadeias causais, a causalidade não mecanicista), os conflitos, entre outros. (GARCÍA RUIZ; GIMÉNEZ; RODRÍGUEZ, 2009, p. 36-37).

Os princípios científico-didáticos têm como ponto de referência comum a vida (inacabamento e provisoriedade) e a dialogicidade. Configuram-se com elos entre si e fazem sentido se forem tratados interdependentemente, visto que, é nas suas relações que habita a vida inerente ao lugar. O princípio da interdependência/conexão/relação acentua essa ideia ao afirmar que "[...] nada existe na Terra que esteja isolado, desconectado, mas tudo está relacionado e entrelaçado, interdependente." (GARCIA RUIZ, 2012, p. 49-50), No lugar e nos entrelugares, numa compreensão dialógica, esse é um argumento fundamental - que viemos propondo -, que se encontra com a "relação entre sujeitos".

Outro aspecto importante a ser considerado é a ideia de "princípio" que se abre às elaborações, portanto servindo como enlace à sustentação da educação integral.

Os princípios são ferramentas, instrumentos de observação, análise, reflexão e compreensão. Constituem a natureza intrínseca dos fenômenos, fatos e acontecimentos. Referem-se tanto aos fatos físicos e naturais como aos sociais e espirituais. Não são conceitos, mas metacategorias dos conceitos. Diferenciam-se destes por sua versatilidade, porque mergulham e subsistem a todos os conceitos e fatos. (GARCÍA RUIZ; GIMÉNEZ; RODRÍGUEZ, 2009, p. 37).

Considerar esses princípios como elos que apreendem proposições sobre o modo como se constroem as compreensões humanas, para sustentar a ideia de lugar, implica assumir o lugar comprometendo-se com a sua singularidade e generalidade. Esse complexo é compreendido, pois, no contexto de espaço entendido como "produto de inter-relações", "esfera da possibilidade da existência da multiplicidade, no sentido de pluralidade coetânea" e "estando sempre em construção", como propõe Massey (2008). O lugar é, então, constituído por relações espaciais entre sujeitos. Nesse sentido,

[...] o que é especial sobre o lugar é, precisamente, esse acabar juntos, o inevitável desafio de negociar um aqui-e-agora (ele mesmo extraído de uma história e de uma geografia de "entãos" e "lás"), e a negociação que deve acontecer dentro e entre ambos, o humano e o não humano. (MASSEY, 2008, p. 203).

"Um sentido global de lugar [...]" (MASSEY, 2012, p. 129) conjuga com o compromisso da perspectiva dialógica e se aproxima da reflexão que colocamos em questão: a respeito do lugar do diálogo, no diálogo do lugar - esse é o desafio da aula de Geografia.

Com os pressupostos indicados, consideramos que a Geografia tem uma preocupação recorrente com a questão. Resultam disso muitos textos reflexivos a respeito dos conceitos e, em especial, do conceito de "lugar". Do ponto de vista da discussão teórica da Geografia e das análises feitas pelos pesquisadores do ensino da disciplina escolar, há um expressivo aumento na produção de ideias que possam basear a questão. No entanto, na escola - quer dizer, no chão da escola -, há muito a fazer. As questões muitas vezes são abordadas de modo mecânico, seguindo sugestões de planos curriculares, de políticas públicas e de livros didáticos.

Com esse panorama, percebe-se que aquilo que mais interessa, ou seja, a aprendizagem significativa, que envolve a produção de conceitos e que tem suas bases na abstração, não acontece. $\mathrm{O}$ ensino se repete sempre do mesmo modo, e a aprendizagem configura ações de reprodução e não de constituição de um saber que dê autonomia aos sujeitos.

O lugar, por sua configuração por meio das relações do sujeito com o mundo, exige compreensão sistemática para evitar a redundância e o senso comum. Estudar o lugar " "....] se caracteriza pela possibilidade de que os estudantes reconheçam a sua identidade e pertencimento em um mundo em que a homogeneidade apresentada pelos processos de globalização trata de tornar tudo igual." (CALLAI, 2011, p. 15). Considerando essa força que o lugar representa na vida dos sujeitos, propomos que o diálogo precisa ser considerado em seu caráter epistemológico e como exercício dialético, no qual o local e o global, o eu e o tu estejam presentes, reconhecidos e entrelaçados.

Ao encontro dessa perspectiva dialógica, Bubnova (2011, p. 271) afirma que "[...] é no processo da comunicação verbal, da interação com o outro, que alguém se faz sujeito forjando seu próprio eu. O 'eu' só existe na medida em que está relacionado a um 'tu'. 'Ser significa comunicar-se', e um 
'eu' é alguém a quem se dirigiu como um 'tu’.' Isso implica assumir que, para os sujeitos sentirem-se parte da aula, identificados pelos elos com o lugar, o diálogo é fundamental. Essa dimensão dialógica compreende a noção teórica de "lugar" e o ensino de Geografia pautado no lugar, pois implica um processo "de interação e de conflito tenso e ininterrupto" (BAKHTIN (VOLOCHINOV), 2004, p. 107).

\section{CONSIDERAÇÕES FINAIS}

Em vez de os alunos entenderem que, com a adoção das salas-ambiente, foram fragilizados e não têm mais lugar na escola, devem compreender que, naquela nova configuração, têm diversos/diferentes lugares, e que isso os fortalece. Essa perspectiva conjuga com algumas constatações finais que nos permitem abrir elementos significativos para o debate acerca dos aportes de lugar à educação integral. Nesse sentido, consideramos que questões gerais podem ser construídas a partir das constatações feitas nas práticas escolares:

- não existe apenas um modo de compreender o mundo; as questões teóricas e metodológicas fundam as nossas verdades e o nosso entendimento;

- o conhecimento (que supõe a dimensão teórica adotada e a necessidade de realizar as abstrações) define a experiência, alimenta-a, dá-lhe substância, permitindo que seja superado o senso comum;

- as verdades não são únicas, mas construídas através das formas de interpretação e, por isso mesmo, precisamos ter as bases teóricas que possam sustentar o nosso estudo - bases que sustentem a leitura do mundo de modo que se tenha argumentação que constitua os entendimentos que vamos construindo.

Nesse contexto, temos como convicção, assim também como proposição, que através da Geografia podem-se compreender os lugares e a ação humana. E, portanto, a Geografia, no conjunto do currículo escolar, tem a finalidade de contribuir para que o aluno construa a sua compreensão da espacialidade do mundo em que vive e, ao mesmo tempo, de oferecer ferramentas intelectuais para promover a análise crítica do espaço. A noção de "lugar" estará sempre presente nessa articulação, que é teórica e que considera o empírico, no sentido de que é fundamental pensar a realidade vivida mas, para fazer essa reflexão, são necessários princípios teóricos e metodológicos que sustentem a análise.

Consideramos, do mesmo modo, que é intransferível a necessidade de que seja superada a fragmentação, o modo como as explicações se contextualizam num quadro mais amplo, para que o aluno consiga perceber o encadeamento das coisas que está fazendo e dos temas que está estudando. Estudar os lugares do mundo (e aqueles com os quais o aluno está vivendo e interagindo) vai além de identificar o que existe: supõe conhecer o que existe, os fenômenos que acontecem e que se expressam no espaço que é construído pelos homens nos processos de sua vida. Isso requer que não se considere apenas o produto, resultado da organização do espaço: é importante e necessário considerar os processos que levam à construção do espaço de modo que os lugares se configurem de um ou outro modo.

Educação integral implica aprendizado que não se restringe apenas às informações, mas, fundamentalmente, se estende à pesquisa, quer dizer, à investigação, ao pensar e refletir, ao fazer perguntas e buscar respostas e, também e especialmente, ao ter perguntas a fazer. Aliás, a arte de fazer perguntas é o caminho que pode ser aberto a partir da tensão que se estabelece entre o conhecimento prévio e o conhecimento científico, de modo a construir o conhecimento novo.

Ter lugar na escola significa, sim, compreender que cada lugar é singular, mas que os lugares são muitos e diferentes entre si. Essa compreensão serve ao empoderamento, pois, no processo de compreensão da espacialidade, contribui à construção das identidades e pertencimentos dos sujeitos. Nesse aspecto, é preciso considerar que o conhecimento que o aluno possui será sempre um conhecimento com um conjunto de informações que fragmenta a realidade; e os aspectos do lugar em que vive se apresentam como realidades concretas. Muitas vezes, falta compreender que são realidades construídas e não dadas pela natureza ou por forças outras.

\section{REFERÊNCIAS}

ANDREIS, A. M. A aula: um território produto-produtor de espaço. In: COLOQUIO INTERNACIONAL DE GEOCRÍTICA EL CONTROL DEL ESPACIO Y LOS ESPACIOS DE CONTROL, 13., 2014, Barcelona. Anais... Barcelona: Universitat de Barcelona, 5-10 maio 2014a.

Cotidiano: uma categoria geográfica para ensinar e aprender na escola. Tese (Doutorado em Educação nas Ciências) - Universidade Regional do Noroeste do Estado do Rio Grande do Sul, Ijuí, RS, fev. 2014b.

\section{BAKHTIN, M. (VOLOCHINOV). Marxismo e filosofia da linguagem. São Paulo: Hucitec, 2004.}

Para uma filosofia do ato responsável. São Carlos, SP: Pedro \& João, 2010.

Problemas da Poética de Dostoiévski. Rio de 
Janeiro: Forense Universitária, 2005.

BRASIL. Educação integral: texto referência para o debate nacional. Brasília, 2009. 52 p.: il. (Série Mais Educação).

BUBNOVA, T. Voz, sentido e diálogo em Bakhtin. Bakhtiniana, São Paulo, n. 6/1, p. 268-280, ago./dez. 2011. Disponível em: <http://www.scielo.br/pdf/bak/v6n1/v6n1a16. pdf $>$. Acesso em: 22 abr. 2012. ISSN 1678-4634.

CALLAI, H. C. Aprendendo a ler o mundo: a Geografia nos anos iniciais do ensino fundamental. Cadernos Cedes, Campinas, v. 25, n. 66, p. 227-247, maio/ago. 2005. Disponível em: <http://www.scielo.br/pdf/ccedes/v25n66/ a06v2566.pdf>. Acesso em: 20 ago. 2014. ISSN 1678-7110.

Em busca de fazer a educação geográfica. In: (Org.). Educação geográfica: reflexão e prática. Ijuí: Unijuí, 2011. p. 15-33.

DOSTOYEVSKI, F. Relatos/1, pobres gentes, el doble. Barcelona, Espanha: Editorial Bruguera S.A., 1976.

GARCÍA RUIZ, A. L. E1 modelo de principios científico-didácticos (PCD): base para la enseñanza y la investigación creativas y significativas de la geografía. Serie Geográfica, Granada/Espanha, n. 18, p. 47-53, 2012. Disponível em: <http://dspace.uah.es/dspace/bitstream/ handle/10017/13321/47_53_modelo_Garc\%C3\%ADa_ SG_2012_N18.pdf?sequence $=1 \&$ is Allowed $=y>$. Acesso em: 21 jul. 2015. ISSN 1136-5277.

; GIMÉNEZ, J.; RODRÍGUEZ, E. Bases teóricas del modelo de principios científico-didácticos para la enseñanza de la geografía y de la historia. Revista Paradigma, Maracay/Venezuela, v. XXX, n. 0 1, p. 31-61, jun. 2009.

HERMANN, N. Hermenêutica e Educação. Rio de Janeiro. DP\&A, 2003.

MASSEY, D. Pelo espaço. Rio de Janeiro: Bertrand Brasil, 2008.

Un sentido global del lugar. Barcelona: Icária,

2012.

SANTOS, M. A natureza do espaço: técnica e tempo. Razão e emoção. São Paulo: Edusp, 2004.
YOUNG, M. O futuro da educação em uma sociedade do conhecimento: a defesa radical de um currículo disciplinar. Cadernos de Educação, Pelotas, n. 38, p. 395-416, jan./ abr. 2011. Disponível em: <http://www.scielo.br/pdf/rbedu/v16n48/v16n48a05.pdf>. Acesso em: 29 jun. 2012.

. Para que servem as escolas? Revista Educação e Sociedade, Campinas, v. 28, n. 101, p. 1287-1302, set./dez. 2007. Disponível em: <http://www.cedes.unicamp.br>. Acesso em: 20 abr. 2011.

Notas de Fim:

1- Em uma aula de Geografia de uma escola urbana e privada na região noroeste do Rio Grande do Sul, no ano de 2008.

2- Escolas que atendem os alunos por mais de quatro horas por dia.

3- Algumas vezes, priorizam-se as reflexões e informações envolvendo outros lugares e, os alunos, desconhecem aspectos marcantes do seu lugar, que poderiam servir como elo às generalizações conceituais.

\section{Correspondência das autoras:}

Adriana Maria Andreis

e-mail: adriana.andreis@uffs.edu.br

\section{Helena Copetti Callai}

e-mail: copetti.callai@gmail.com

Artigo recebido em: 06/06/2016

Revisado pelo autor em: 07/05/2017

Aceito para publicação em: 26/07/2017 